九州大学学術情報リポジトリ

Kyushu University Institutional Repository

Cytotoxic Effects and Androgen Receptor Expression According to Concentrations of Genistein with Silencing Cyclooxygenase-2 Gene Expression in Prostate Cancer Cells

Kim, Jin Woo

Research Institute, Panagene Inc.

Gotoh, Takafumi

Kuju Agricultural Research Center, Faculty of Agriculture, Kyushu University

Lim, Hyoun-Sub

Department of Applied Biology, College of Agriculture and Life Sciences

Song, Ki Hak

Department of Urology, School of Medicine, ChungnamNational University

他

https://doi.org/10.5109/1467631

出版情報: 九州大学大学院農学研究院紀要. 59 (2)，pp.289-296，2014-08-29. Faculty of Agriculture, Kyushu University

バージョン：

権利関係 : 


\title{
Cytotoxic Effects and Androgen Receptor Expression According to Concentrations of Genistein with Silencing Cyclooxygenase-2 Gene Expression in Prostate Cancer Cells
}

\author{
Jin Woo KIM ${ }^{1}$, Takafumi GOTOH ${ }^{2}$, Hyoun-Sub LIM ${ }^{3}$, \\ Ki Hak SONG ${ }^{4 *}$ and Chong Koo SUL ${ }^{4}$
}

\author{
Kuju Agricultural Research Center, Faculty of Agriculture, \\ Kyushu University, Kuju, Oita, Japan \\ (Received April 25, 2014 and accepted May 12, 2014)
}

\begin{abstract}
COX-2 has major roles in inflammatory reaction, and COX-2 inhibitor and genistein have a chemopreventive effect on some cancers such as colorectal, breast, and prostate cancer (PCa). The aims of this study was to investigate combined effect of COX-2 inhibition and genistein treatment. To address this issue, we tested the degree of cell survival and the changes of androgen receptor in PCa cells with silencing of COX-2 according to concentrations of genistein.

DU-145 PCa cells were transfected with COX-2 siRNA. The mRNA expressions of androgen receptor and caspase-3 were detected using reverse transcription polymerase chain reaction in the cells with or without COX-2 siRNA transfection. Immunofluorescent staining was performed on PCa cell with COX-2, androgen receptor and caspase-3 antibody and analyzed with confocal microscopy and image analyzer. Cell cytotoxicity according to concentrations of genistein was analyzed with MTT assay.

The mRNA expression of AR was down-regulated in DU-145 cell line according to concentration of genistein, but caspase-3 expression showed up-regulated pattern in increasing the dosage of genistein. COX-2 siRNA (+) group was stronger mRNA expression of caspase-3 and weaker mRNA expression of AR than COX-2 siRNA (-) group. The immunofluorescent staining results were similar with those of mRNA expression. The results of cell survival showed that COX-2 siRNA $(+)$ group with genistein was more cytotoxic compared to COX-2 siRNA (-) group (Repeated Measured ANOVA, p=0.004). There was significant cytotoxic effects in COX-2 siRNA (+) group between $10 \mu \mathrm{M}$ and $50 \mu \mathrm{M}$ of concentration of genistein compared to COX-2 siRNA $(-)$ group $(\mathrm{p}<0.0001)$.

The effect of genistein and silencing of COX-2 shows that it reduced AR and increased caspase-3 in PCa cells. These results suggest that genistein and silencing of COX-2 might be a role in the inhibition of cell proliferation and induction of apoptosis
\end{abstract}

Key words: Androgen receptors, Caspase 3, Cyclooxygenase 2, Genistein, Small interfering RNA

\section{INTRODUCTION}

Inflammation is a major reaction of natural immunity against infectious agents such as viruses and bacteria, entrance of antigen like as lipopolysaccharides and cell damages induced by UV irradiation and chemicals. (Kulinsky, 2007). Dubois et al. (1998). reported that osteoarthritis, Crohn's disease and cancer were related to chronic inflammation and recently more data support their theory that inflammation is closely related to the incidence of rectal, breast, and prostate cancers. (Howe, 2007; Coussens and Werb, 2002; Fujiiet al., 2013). As shown by supportive data, Coussens and Werb (2002). reported that the chronic inflammation resulting from infective agents, environmental factors and complex components may induce the malignancies and upwards of $15 \%$ of malignancies worldwide can be attributed to infections.

Research Institute, Panagene Inc. Daejeon, Republic of Korea Kuju Agricultural Research Center, Faculty of Agriculture, Kyushu University

Department of Applied Biology, College of Agriculture and Life Sciences

${ }^{4}$ Department of Urology, School of Medicine, Chungnam National University, Daejeon, Republic of Korea

* Corresponding author (E-mail: urosong@cnu.ac.kr)
Cyclooxygenase-2 (COX-2) is an inducible enzyme that produced by inflammatory cytokine, endotoxin and growth factor such as TNF $\alpha$ and induced nuclear factor kappa B (NF-kB) in apoptosis pathway. (Khan et al., 2011). Several experimental and clinical studies have established NSAID (Non-steroidal anti-inflammatory drugs) may have a potent anti-cancer activity. Specifically, COX-2 inhibitors have been applied for prevention and therapeutic modality against breast, colorectal, and lung cancer. (Falandry et al., 2009; Eisinger et al., 2007; Mutter et al., 2009). These trials also have been applied in prostate cancer and the factors and mechanisms causing prostate cancer based on the knowledge of epidemiology, histopathology, and molecular biology have been studied. (De Marzo et al., 2004; Platz and De Marzo, 2004).

Androgen, a group of male steroid hormones, have important role in regulating development of prostate and growing of prostate cancer by binding to androgen receptor (AR) (Taplin and Balk, 2004). Therefore, hormone therapy that reduce androgen level or to prevent it from reaching prostate cancer cells in prostate cancer patient, is frequently selected as a first line treatment. This therapy makes shrink or slow grow of prostate cancers for a while. However, this hormone therapy often failed with appearance of castrate-resistant prostate cancer that 
frequently showed increased level of AR expression. Recent study demonstrated that a second-generation antiandrogen enzalutamide inhibited cell growth and induced apoptosis in AR gene amplified prostate cancer cells (Tran et al., 2009). Isoflavone phytoestrogen called genistein found in soybean has several effects such as a weak estrogen effect, (Kuiper et al., 1997). inhibition of 5-alpha-reductase and aromatase enzymes. (Evans et al., 1995). Furthermore, genistein may have an important role to inhibit angiogenesis required for tumor growth (Harper et al., 1996; Folkman and Shing, 1992). while maintaining the effect of an antioxidant. (Rice-Evans et al., 1995). However, there is no information related the effect of genistein on treated COX-2 silenced prostate cancer cells. In order to demonstrate such an effect, and find more information to understand inflammation and prostate cancer, genistein was chosen for this study. In this study, we evaluated whether silencing of COX-2 in prostate cancer cells affected on apoptosis (change of caspase-3 level) and the expression of AR after treatment with various genistein concentrations. Finally, our data indicate that combination of COX-2 gene silencing and genistein is better treatment option for prostate cancer.

\section{MATERIALS AND METHODS}

\section{Culturing prostate cancer cell line}

Cell lines DU-145 (KCLB No. 30081) and PC3 (KCLB No. 21435) from the Korean Cell Line Bank were used for this study. Cells were grown in $100 \times 15 \mathrm{~mm}$ petri dishes nourished by RPMI 1640 (R8758, Sigma-Aldrich, St. Louis, MO, USA) supplemented with L-glutamine $(0.3 \mathrm{~g} / \mathrm{L}), \mathrm{NaHCO}_{3}(2.0 \mathrm{~g} / \mathrm{L})$, and $10 \%$ of Fetal Bovine Serum (FBS, Cat No. 16000036, Invitrogen, Carlsbad, CA. USA). Growth conditions with supplement 5\% $\mathrm{CO}_{2}$ were maintained at $37^{\circ} \mathrm{C}$ with optimal humidity.

\section{COX-2 siRNA transfection}

$2 \mathrm{ml}$ of cell culture suspension $\left(1 \times 10^{5}\right.$ cells $\left./ \mathrm{ml}\right)$ in absence of antibiotics were distributed to six well plates and were grown under $5 \% \mathrm{CO}_{2}$ supplied incubator at $37^{\circ} \mathrm{C}$ for 18-24 hours. The COX-2 siRNA was synthesized as antisense oligonucleotides designed from the human COX-2 gene (GenBank Acc. No. NM_000963.2), and three 40-52\% GC content antisense oligonucleotides were used for siRNA transfection (Table 1). Solution A was prepared by mixing $200 \mu \mathrm{l}$ of OPTI-MEM I (Cat. No. 31985, Invitrogen, Carlsbad, CA, USA) containing 30 pmole siRNA (Invitrogen, Carlsbad, CA, USA), $5 \mu$ l of Lipofectamine RNAiMAX Reagent (Cat. No. 13778-075, Invitrogen, Carlsbad, CA, USA), and was maintained under room temperature for $20 \mathrm{~min}$. The $1.8 \mathrm{ml} \mathrm{OPTI-}$ MEM I mixed with $0.2 \mathrm{ml}$ of solution A was grown at each well for 48 hours at $37^{\circ} \mathrm{C}$ with supplement of $5 \% \mathrm{CO}_{2}$. For control $2 \mathrm{ml}$ of OPTI-MEM was cultured at the same condition. One ml culture mixed with $20 \%$ diluted FBS containing 2 times higher concentration of antibiotics was added to the well plate, and new culture media was supplied each 24 hours.

\section{Confirming COX-2 siRNA transfection using immunofluorescence staining}

The COX-2 siRNA transfected cells were transferred to chamber slide (177399, Thermo Fisher Scientific Inc., Rochester, NY, USA) which was cultured overnight in order to bring the cells to confluence. After overnight culture cells were washed with PBS and fixed using 3.6\% formaldehyde (Samchun Chemical, Seoul, Korea) for 10 min, then washed again in PBS buffer. The fixed chamber slide was treated with $0.1 \%$ of Triton $\mathrm{X}-100$ (T-8532, Sigma-Aldrich, St. Louis, MO, USA) for $5 \mathrm{~min}$ and was again washed with PBS, prior to blocking with 10\% normal donkey serum (sc-2044, Santa Cruz Biotechnology, Inc., Dallas, TX, USA). After 1 hour incubation at $37^{\circ} \mathrm{C}, 400$ times diluted antibody against COX-2 (goat polyclonal, sc-1746, Santa Cruz Biotechnology, Inc., Dallas, TX, USA) was reacted with cell embedded chamber slide overnight at $4^{\circ} \mathrm{C}$. Slides were washed with PBS twice for $5 \mathrm{~min}$ each to remove the COX-2 antibody before adding secondary antibody of anti-goat IgG FITC (1:400, sc-2024, Santa Cruz Biotechnology, Inc., Dallas, TX, USA). In order to stain the nucleus, 400 times diluted 4', 6-diamidino-2-phenyl indole (DAPI, Sigma-Aldrich, St. Louis, MO, USA) was reacted for 1 hour at $37^{\circ} \mathrm{C}$, then washed three times for $5 \mathrm{~min}$ each time with PBS. The stained chamber slides were scanned by confocal microscopy using a LSM 710 (Carl Zeiss Inc., Jena, Germany)

\section{Isolation of total RNA for assay of COX-2, cas- pase-3, and AR mRNAs}

The $0.5 \mathrm{ml}$ of cell culture suspension was added with $0.8 \mathrm{ml}$ of Trizol (15596-018, Invitrogen, Carlsbad, CA, USA) for $5 \mathrm{~min}$ at room temperature. $0.16 \mathrm{ml}$ of chloroform was added to this tube, mixed, and centrifuged for $20 \mathrm{~min}$ at 13,200 rpm. The $0.5 \mathrm{ml}$ supernatant was mixed with $1 \mathrm{ml}$ of isopropyl alcohol (I-0398, Sigma-Aldrich, St. Louis, MO, USA) for RNA precipitation. After a 70\% ethanol wash, clean RNA was collected by centrifugation (13,200 rpm, $30 \mathrm{~min}$ ), dissolved in $60 \mu \mathrm{l}$ of DEPC water, and RNA concentration was measured by Nano spectrometer (Amersham Biosciences, Buckinghamshire, England).

Table 1. Sequences of antisense oligonucleotide for silencing of COX-2 gene

\begin{tabular}{lccc}
\hline & Sequences & GC\% & start location of ORF \\
\hline PTGS2-HSS108792 & 5'-GAGTTATGTCTTGACATCCAGATCA-3' & $40.0 \%$ & 432 \\
PTGS2-HSS183840 & 5'-GAAGCCTTCTCTAACCTCTCCTATT-3' & $44.0 \%$ & 510 \\
PTGS2-HSS183839 & 5'-TCCAGACAAGCAGGCTAATACTGAT-3' & $44.0 \%$ & 1078 \\
\hline
\end{tabular}




\section{RT-PCR}

Complementary DNA was synthesized by using RT kit (Takara Bio Inc., Shiga, Japan). For amplifying of COX2, primers F-5'-TTC AAA TGA GAT TGT GGA AAA ATT GCT-3' and R-5'-AGA TCA TCT CTG CCT GAG TAT CTT-3' were used. Caspase-3 DNA was synthesized using F-5'-CCG AAA GGT GGC AAC AGA AT-3' and R-5'-ATG CCC ACA GAT GCC TAA GT-3'. Oligomers F-5'-TCC AAG ACC TAC CGA GGA GCT-3' and R-5'TGT GAA GGT TGC TGT TCC TCA TC-3' were used for synthesizing DNA of AR. For producing DNA of glyceraldehyde 3-phosphate dehydrogenase (GAPDH), primers F-5'-CGG GGC TCT CCA GAA CAT CAT CC-3' and R-5'-CGA CGC CTG CTT CAC CAC CTT CTT-3' were used. PCR reaction was performed with SolGent PCR kit (SolGent, Daejeon, Korea) containing $2 \mu \mathrm{l}$ of cDNA, $4 \mu \mathrm{l}$ of $5 \mathrm{X}$ buffer, $0.1 \mu \mathrm{l}$ of Taq polymerase, 10 pmole specific primer for each of target genes, and water to fit $20 \mu \mathrm{l}$ of final volume, and was programmed by three steps consisted of $95^{\circ} \mathrm{C}$ for $5 \mathrm{~min}, 35$ cycles of $95^{\circ} \mathrm{C}$ for $30 \mathrm{sec} / 60^{\circ} \mathrm{C}$ for $40 \mathrm{sec} / 72^{\circ} \mathrm{C}$ for $30 \mathrm{sec}$, and $72^{\circ} \mathrm{C}$ for $5 \mathrm{~min}$. The size of PCR products were visualized using $2 \%$ agarose electrophoresis gel. UV detected DNA was measured for DNA size using BIO-ID program.

\section{Immunofluorescence staining of caspase- $-3, \mathrm{AR}$, and COX-2}

The transfected cells were treated using the same procedure indicated above, before adding immunofluorescent antibody for caspase-3, AR and COX-2. Two slides were prepared for staining COX-2 and caspase-3 immunofluorescence, and the other for COX-2 and AR immunofluorescence. Each chamber slide was reacted at $4^{\circ} \mathrm{C}$ overnight with respect to primary antibodies of AR (1:400, sc-7305, mouse monoclonal, Santa Cruz Biotechnology, Inc., Dallas, TX, USA), caspase-3 (1:400, sc-7148, rabbit polyclonal, Santa Cruz Biotechnology, Inc., Dallas, TX, USA), and COX-2 (1:400, sc-1746, goat polyclonal, Santa Cruz Biotechnology, Inc., Dallas, TX, USA). Overnight reacted slide chamber was washed twice with PBS, then secondary antibodies were added. These secondary antibodies as follow; for staining AR and COX-2, donkey antimouse IgG Texas Red (TR) (1:400, sc-2785, Santa Cruz Biotechnology, Inc., Dallas, TX, USA) and donkey antigoat IgG fluorescein isothiocyanate (FITC) (1:400, sc-2024, Santa Cruz Biotechnology, Inc., Dallas, TX, USA) were used, and for staining COX-2 and caspase-3, donkey anti-goat IgG FITC (1:400, sc-2024, Santa Cruz Biotechnology, Inc., Dallas, TX, USA) and donkey antirabbit TR (1:400, sc-2784, Santa Cruz Biotechnology, Inc., Dallas, TX, USA) were applied. In order to stain the nucleus, DAPI (Sigma-Aldrich, St. Louis, MO, USA) solution was also added to chamber slide. After washing three times with PBS each slide was analyzed by confocal microscopy 710 .

\section{Evaluating prostate cancer cell survival in propor- tion to various genistein concentrations}

COX-2 siRNA transfected cell suspensions and nontransfected cell suspensions were counted using a hemo- cytometer and distributed evenly at a concentration of $2 \times 10^{4}$ cells to each of 96 wells, then the plate were incubated at $37^{\circ} \mathrm{C}$ for 24 hours at $5 \% \mathrm{CO}_{2}$. Genistein (G6776, Sigma-Aldrich, St. Louis, MO, USA) dissolved in dimethyl sulfoxide (DMSO) was added to wells at a concentration of $0,10,25,50,100$, and $200 \mu \mathrm{M}$ respectively. Genistein supplemented plates were cultured at $37^{\circ} \mathrm{C}$, and $5 \% \mathrm{CO}_{2}$ in an incubator for 24 hours. After 24 hours culture the supernatants were removed from each well and $100 \mu \mathrm{l}$ of MTT (3-(4,5-Dimethylthiazol-2-yl)-2,5diphenyl tetrazolium bromide) solution added per well and reacted for 4 hours. After carefully washing the plate with PBS to remove MTT, each well was treated with $200 \mu \mathrm{l}$ of DMSO and the plate was shaken for 15 to $20 \mathrm{~min}$. The absorbance from each well was analyzed at $450 \mathrm{~nm}$ using a plate reader.

\section{Statistical analysis}

Data were analyzed based on repeated measured ANOVA. A p-value $<0.05$ was considered statistically significant. All the tests in this article were implemented using IBM SPSS Statistics Ver. 20.0 (SPSS Inc., Chicago, IL, USA).

\section{RESULTS}

\section{Confirming COX-2 siRNA transfected cell by using immunofluorescence}

DU-145 prostate cancer cell line showed higher transfection rate of as much as 60-70\% compared to a $40 \%$ transfection rate for PC3 prostate cancer cell line (Fig.
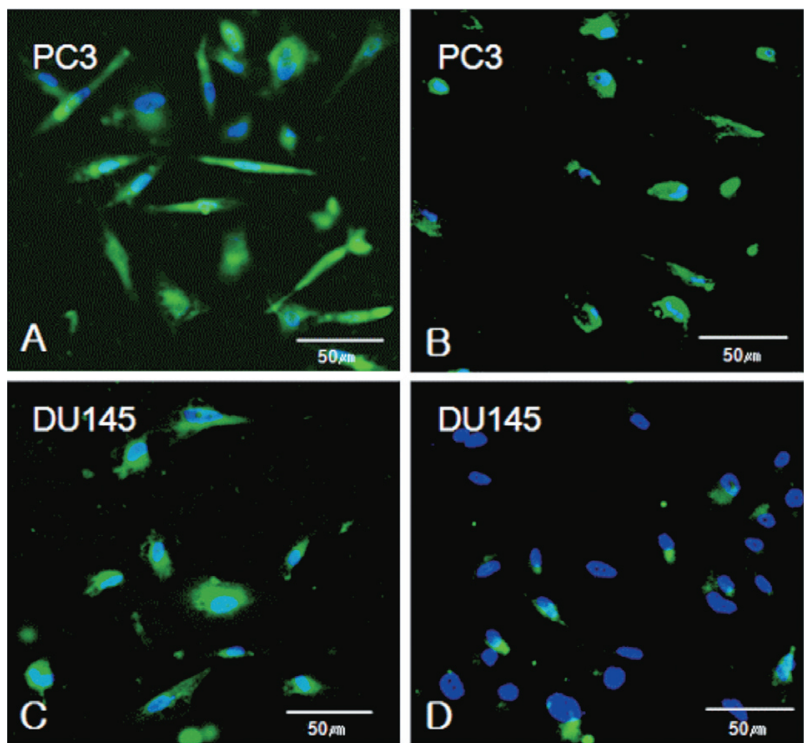

Fig. 1. Expression of COX-2 in different prostate cancer cell lines. COX-2 expressions after COX-2 siRNA transfection (B, D) were weaker than without COX-2 siRNA transfection (A, C). DU-145 cell line shows weaker immunoreactivity of COX-2 than PC3 cell line after COX-2 siRNA transfection. A. PC3 prostate cancer cell line without COX-2 siRNA, B; PC3 prostate cancer cell line with COX-2 siRNA, C; DU-145 prostate cancer cell line without COX-2 siRNA, D; DU-145 prostate cancer cell line with COX-2 siRNA. [Blue = DAPI stained nuclei; Green = FITC-labeled secondary antibody revealing localization of COX-2 specific primary antibody]. 
1). Green color represented COX-2 antibody by FITC and blue color indicated DAPI staining of nucleus. In COX-2 siRNA transfected cell (Fig. 1B, 1D), green fluorescence area diminished comparing to non-transfected prostate cancer cell line of PC3 and DU-145.

mRNA expression of AR and caspase-3 in proportion to the concentration of genistein

Little effect of increasing genistein concentration was observed on expression levels of AR mRNA in the DU-145 prostate cancer cell line in the absence of COX-2 siRNA treatment, whereas COX-2 siRNA treated cells showed lower mRNA expression of AR than that in absence of siRNA treatment. We also tested expression level of caspase-3 as an indicator for apoptosis. Messenger RNA expression of caspase-3 increased in proportion to concentration of genistein concentration in COX-2 siRNA

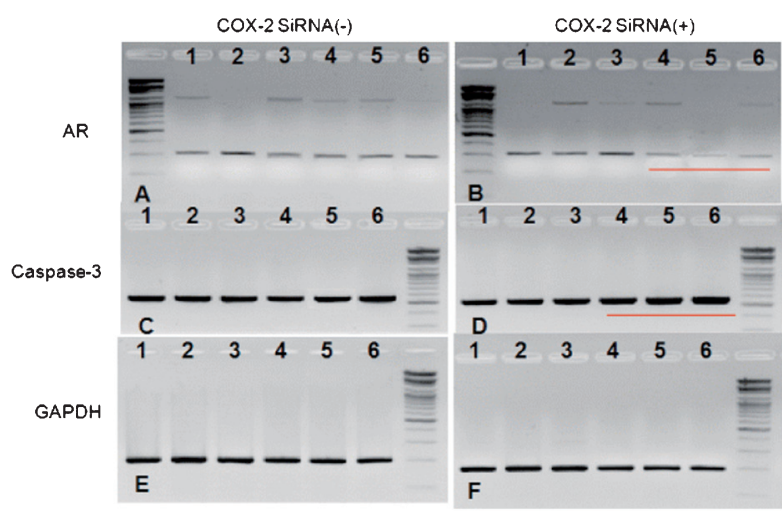

Fig. 2. mRNA expression levels of AR, caspase-3, and GAPDH in DU-145 prostate cancer cell line according to concentrations of genistein. mRNA expression levels of caspase-3 in COX-2 siRNA $(+)$ group were stronger than COX-2 siRNA $(-)$ group at high concentrations of genistein. 1; control, 2 ; DMSO $(0 \mu \mathrm{M}), 3 ; 10 \mu \mathrm{M}, 4 ; 25 \mu \mathrm{M}, 5 ; 50 \mu \mathrm{M}, 6$; $100 \mu \mathrm{M}, \mathrm{AR}$; androgen receptor. A; AR without COX-2 siRNA, B; AR with COX-2 siRNA, C; caspase-3 without COX-2 siRNA, D; caspase-3 with COX-2 siRNA, E; GAPDH without COX-2 siRNA, F; GAPDH with COX-2 siRNA. transfected prostate cancer cell lines (Fig. 2)

\section{Immunofluorescence of caspase- 3 and $A R$ resulting from COX-2 siRNA transfection}

Caspase-3 production dependence on genistein concentration between COX-2 siRNA treated and nontreated cells was analyzed by confocal microscopy to detect fluorescence binding to caspase-3 antibody. Cells were visualized by green indicating DAPI, red representing caspase- 3 and blue where COX-2 antibody bind. The intensity of immunofluorescence of caspase-3 was increased in proportion to concentration of genistein, and it showed higher level of caspase-3 immunofluorescence in COX-2 siRNA transfected prostate cancer cell lines as same as mRNA expression level of caspase-3 (Fig. 3). In addition, in COX-2 siRNA transfected cell line mRNA expression and protein production of $\mathrm{AR}$ decreased as concentration of genistein increased (Fig. 4).

\section{Evaluating cell viability rate in proportion to con- centration of genistein}

In DU-145 prostate cancer cell lines, the effect of COX-2 siRNA transfection on survival rate (Cell viability) was analyzed by MTT assay. Both siRNA treated and non-treated cell lines showed decrease survival rate according to high level of genistein treatment. There was significant difference of survival rate above $50 \mu \mathrm{M}$ genistein concentration $(\mathrm{p}<0.05)$. In case of siRNA treated cell, survival rate of cell line show significantly different above $10 \mu \mathrm{M}(\mathrm{p}<0.05)$. Through these experiments we proved that genistein affect survival rate of cell line and at $10 \mu \mathrm{M}$ and $25 \mu \mathrm{M}$ genistein significantly reduced survival rate $(p<0.0001)$ in COX-2 siRNA transfected cell lines. At higher than $50 \mu \mathrm{M}$ of genistein, COX-2 siRNA treated cells showed relatively low rate of cell survival than control group (without COX-2 siRNA transfection), but the difference was not statistically significant ( $p>$ 0.05) (Fig. 5).

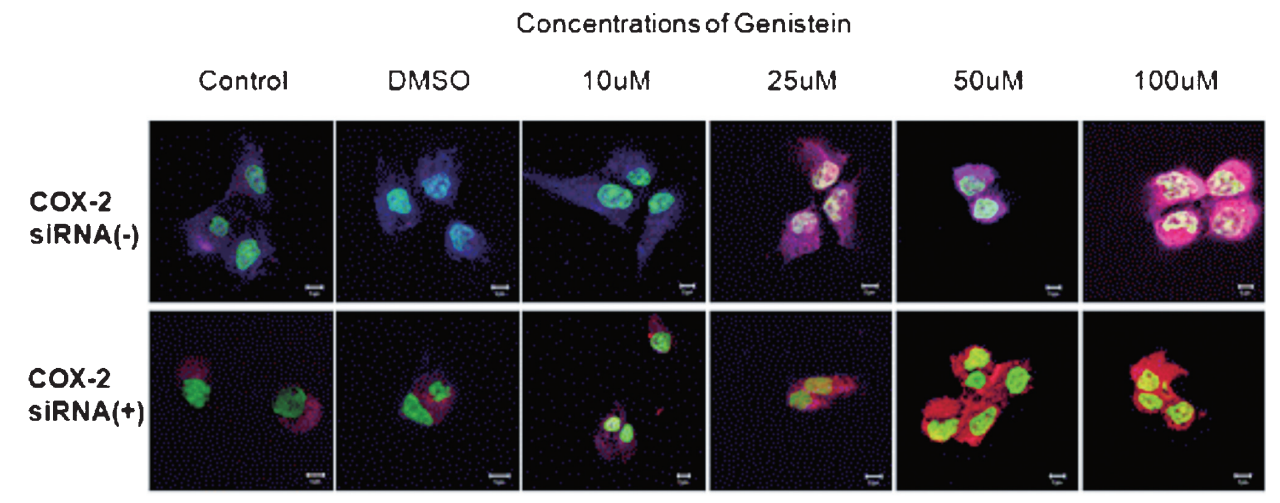

Fig. 3. Merged images of expression of caspase- 3 and COX -2 according to concentrations of genistein on COX -2 siRNA $(-)$ and COX -2 siRNA (+). The expression of caspase- 3 in DU-145 prostate cancer cell line was increased in state of increasing dose of genistein and the expression of caspase- 3 in DU-145 prostate cancer cell line with silencing of COX-2 was more increased in state of increasing dose of genistein compared to in DU-145 prostate cancer cell line without silencing of COX-2. DAPI (green), COX-2 (blue), caspase-3 (red). 


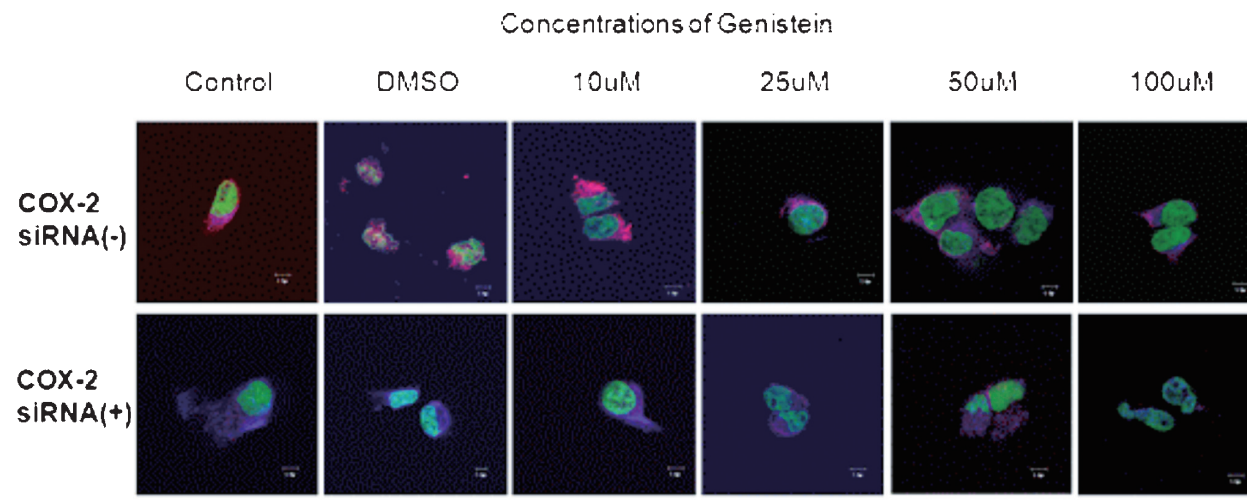

Fig. 4. Merged images of expression of Androgen receptor (AR) and COX-2 according to concentrations of genistein on COX-2 siRNA $(-)$ and COX-2 siRNA $(+)$. The expression of AR in DU-145 prostate cancer cell line was decreased in state of increasing dose of genistein and the expression of AR in DU-145 prostate cancer cell line with silencing of COX-2 was more decreased in state of increasing dose of genistein compared to in DU-145 prostate cancer cell line without silencing of COX-2. DAPI (green), COX-2 (red), AR (blue)

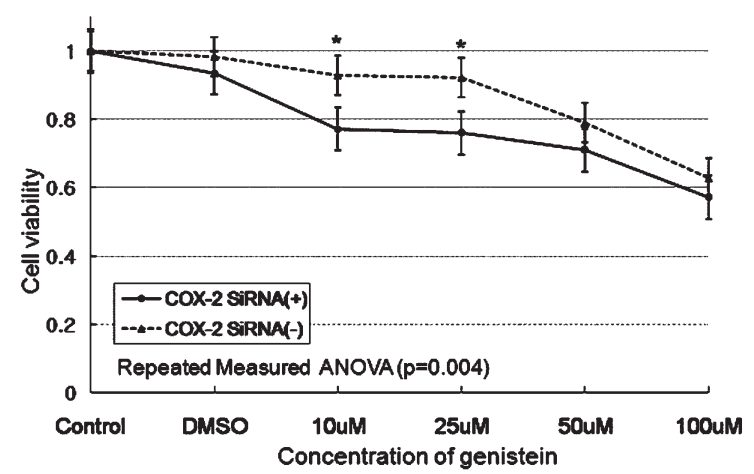

Fig. 5. Results of cell survival according to concentrations of genistein by MTT assay. COX-2 siRNA (+) group showed lower cell viability compared to COX-2 siRNA (-) group (repeated measured ANOVA, $\mathrm{p}=0.004$ ).There are significant differences in cell viability on $10 \mu \mathrm{M}$ and $25 \mu \mathrm{M}$ of concentrations of genistein $(* ; p<0.05)$.

\section{DISCUSSION}

Prostate cancer is a critical public health problem in western countries because it is represented the highest prevalence rate and the second mortality in men's cancer (Siegel et al., 2012). In South Korea, the incidence of prostate cancer has been dramatically increased last 10 years, so active studies of the disease have been significantly expanded (Park et al., 2006). For treatment of prostate cancer, anti-androgen therapy has been used standard therapy in advanced cases, and a recent study showed that prostate cancer incidence is related to inflammation, thus the relationship of these two factors has been examined for cancer treatment (Sobolewski et al., 2010). However, in the study of inflammation and prostate cancer we have not yet found direct evidence for a relationship between cancer and inflammation. The relationship between inflammation and cancer was revealed through clinical data resulting from long-term treatment with nonsteroidal anti-inflammatory drug (NSAIDs) indicating that incidence of colon cancer and rectal cancer were reduced (Yao et al., 2004). Furthermore, DuBois and Smalley (1996) reported that taking aspirin for long period reduces incidence of colon cancer and rectal cancer by as much as fifty percent. Now NSAIDs such as sulindac or celecoxib were approved by the US FDA and had been used for chemoprevention of adenomatous polyposis coli caused by mutation of tumor suppressor gene (Eisinger et al., 2007; Steinbach et al., 2000; Phillips et al., 2002).

Chemoprevention for prostate cancer has been to change dietary habits or inject natural or synthesized substances to inhibit one of the processes involved in cancer development or to reverse existing damage. In the case of prostate cancer, chemical preventive therapy is important because prostate cancer typically has very high incidence rate with the property of very slowly progressing to invasive cancer, and environmental factors contribute to development from latent to clinically diagnosed cancer. One of the environmental factors is isoflavone from a soybean diet and men with a high intake of soybean have a low rate of prostate cancer incidence. Therefore soybean is one of the known chemically preventive foods (Kurahashi et al., 2007). Soybean is a traditional food in Korea and Japan, and it has been thought to be one of the reasons for low incidence rate in Korea comparing to western countries. Genistein in soybean is the main phytoestrogen to prevent not only prostate cancer but also breast cancer and rectal cancer, and it has been reported as a notable preventive chemical. Thus, in this research our goals were to reveal that how inflammation inducing COX-2 and preventive chemical compound genistein function in response to changes in the $\mathrm{AR}$ and cell survival in prostate cancer cells.

Since treatment with NSAIDs such as aspirin and sulindac in colorectal cancer was reported to reduce the mortality rate caused by colon cancer in the late 1990's, it has been attractive significant research goal to suppress COX-2 in order to inhibit cancer incidence. The pathways of tumor induction by COX-2 are through controlling prostaglandin production, apoptosis, and cancer 
cell metastasis (Gallo et al., 2001; Uefuji et al., 2000; Masferrer et al., 2000; Daniel et al., 1999). Also, Uefuji et al. (2000) reported that overexpressed COX-2 was associated with increased prostaglandin E2 biosynthesis and angiogenesis in gastric cancer, and Tsujii et al. (1997) found that overexpressed COX-2 induces the reactivity of metalloproteinase-2, which caused phenotypic changes altering the metastatic potential of colorectal cancer cells. Furthermore, Chan et al. (2007) showed COX-2 expression interference by siRNA exhibited anti-proliferative effect on gastric cancer cells.

Palayoor et al. (1998) reported the use of NSAIDs (ibuprofen) enhanced the efficacy of radiation in prostate cancer cell and the efficacy was related with the dosage of ibuprofen. And in order to reduce the side effects of NSAIDs, the suppression of COX-2 by siRNA was used in next study but it did not alter radiosensitivity in prostate cancer cells (Palayoor et al., 2005). Previous evidence showing COX-2 inhibition affecting mechanisms of tumor growth supported that efficacy of treatments with either chemotherapy or radiation might be augmented and it could be enhanced prevention of cancer progression.

Two significant pathways induce cell death, of which one is caused by an internal pathway involved in mitochondria induced by damaged cells and the other by external pathway with TNF (tumor necrosis factor) -induced and the Fas-Fas ligand-mediated pathway. Meanwhile, suppression of COX-2 played a role in both pathways to induce cell death. Liu et al. (1998) found that an androgen-sensitive prostate cancer cells which highly expressed COX-2 could be changed to apoptotic cell by COX-2 suppressor NS-398 inducing inhibition of $\mathrm{Bcl}-2$. Cell death and caspase activation was inhibited by Bcl-2 family inhibiting the production of the factor such as cytochrome c to turn on cell death (Marcelli et al., 2000; Marcelli et al., 1999). Based on Bcl-2 gene, Hsu et al. (2000) revealed that COX-2 is constitutively expressed in androgen-sensitive LNCaP and androgen-insensitive PC3 cells and that COX-2 inhibitor, celecoxib, induced apoptosis by blocking Akt phosphorylation independently of Bcl-2. The inhibition of COX-2 and Bcl-2 might affect the initiating of apoptosis therefore we evaluated whether COX-2 affect the programmed cell death in androgen insensitive DU-145 prostate cancer cells using siRNA of COX-2. And we included caspase-3 in our study in order to investigate not only the apoptosis mechanism but also to evaluate cell death efficiency as chemical preventive in COX-2 siRNA suppressed prostate cancer cells. Through our research we found that siRNA treated cells showed high expression of caspase-3, and as genistein dosage increased the expression of caspase also increased. Therefore we assumed suppression of COX-2 enhanced efficiency of cell death with co-treatment of genistein.

Androgen has an important role in development and proliferation of prostate and it is converted dehydroxytestosterone (DHT) by 5-alpha reductase. DHT-AR complex induced transcription of DNA and produce several substances such as TGF-beta, Insulin-like growth fac- tor, epidermal growth factor, PDGF and so on that affect proliferation and development in prostate cell (Rizzo et al., 2005).

The findings in this research that inhibition of COX-2 suppress the expression of AR was in accordance with the results of Narayama et al. (2006) indicating that treatment with COX-2 siRNA in mouse prostate cancer cell lines (TR-75) and human PC3 prostate cancer cell stops the cell growth caused by high activity of cell division in G1-S phase and expression of the AR decreased in TR-75 cell but the change of AR expression was not identified in PC3. We thought one of this reasons why AR expression did not change in PC3 cells that it was poorly differentiated cancer cell than DU-145 cell and another reason was different activity of 5-alpha reductase in PC3 cells.

Peterson and Barnes (1993) reported that genistein inhibited cell growth of both hormone dependent and independent cells with respect to LNCaP and DU-145. In addition, Gellar et al. (1998) showed that the concentration of genistein in the range of $1.25-10 \mu \mathrm{g} / \mathrm{ml}$ has the effect of suppressing growth of both benign prostatic hyperplasia and prostate cancer in histoculture. Newly introduced genistein effect on prostate cancer treatment has been frequently reported, however the mechanism by which genistein inhibits growth was not clearly revealed except that it is not through the EGF-receptor tyrosine kinase. Recent data from Li et al. (2008) and Oh et al. (2010) gave the clues that inhibiting cell growth and suppressing expression of AR resulted from genistein inhibition of AR expression, and regulated Akt/PKB serine/threonine kinase including nuclear factor kappa B and EGFRAkt/p70S6k. At the same time we showed that survival rate of COX-2 siRNA treated prostate cancer cell significantly decreased compared to non-treated cells, and genistein treated cells depending on its concentrations ( $25 \mu \mathrm{M}-50 \mu \mathrm{M})$ were affected on survival rate; however higher concentration of genistein $(100 \mu \mathrm{M})$ had no benefit on cell survival. From these results, we assume that genistein contributes to cell death rather than having an effect by inhibition of COX-2, but decrease of AR expression may result from both COX-2 suppression and genistein effect.

In summary, through our research data indicating COX-2 suppression and genistein effect on AR expression and cell vitality rate, we suggest that genistein may be valuable as an alternative cancer treatment, specifically in prostate cancer for clinical purposes.

\section{ACKNOLWDEGEMENT}

This research was supported by iPET(Korea Institute of Planning and Evaluation for Technology in Food, Agriculture, Forestry and Fisheries), Ministry of Agriculture, Food and Rural Affairs (Project No. 1102183)

\section{REFERENCES}

Chan, M. W., C. Y. Wong, A. S. Cheng, V. Y. Chan, and W. K. Leung 2007 Targeted inhibition of COX-2 expression by RNA inter- 
ference suppresses tumor growth and potentiates chemosensitivity to cisplatin in human gastric cancer cells. Oncol. Rep., 18: $1557-62$

Coussens, L. M., and Z. Werb 2002. Inflammation and cancer. Nature, 420: $860-7$

Daniel, T. O., H. Liu, J. D. Morrow, B. C. Crews, and L. J. Marnett 1999 Thromboxane A2 is a mediator of cyclooxygenase-2-dependent endothelial migration and angiogenesis. Cancer Res., 59: $4574-7$

De Marzo, A. M., T. L. DeWeese, E. A. Platz, A. K. Meeker, M. Nakayama, J. I. Epstein, W. B. Isaacs, and W. G. Nelson 2004 Pathological and molecular mechanisms of prostate carcinogenesis: implications for diagnosis, detection, prevention, and treatment. J. Cellular Biochem., 91: 459-77

Dubois, R. N., S. B. Abramson, L. Crofford, R. A. Gupta, L. S. Simon, B. A. Leo, Van De Putte L. B., and P. E. Lipsky 1998 Cyclooxygenase in biology and disease. FASEB J., 12: 1063-73

DuBois, R. N., and W. E. Smalley 1996 Cyclooxygenase, NSAIDs, and colorectal cancer. J. Gastroenterol., 31: 898-906

Eisinger, A. L., S. M. Prescott, D. A. Jones, and D. M. Stafforini 2007 The role of cyclooxygenase-2 and prostaglandins in colon cancer. Prostaglandins Other Lipid Mediat... 82:147-54

Evans, B. A., K. Griffiths, and M. S. Morton 1995 Inhibition of 5 alpha-reductase in genital skin fibroblasts and prostate tissue by dietary lignans and isoflavonoids. J. Endocrinol., 147: 295-302

Falandry, C., P. A. Canney, G. Freyer, and L. Y. Dirix 2009 Role of combination therapy with aromatase and cyclooxygenase-2 inhibitors in patients with metastatic breast cancer. Ann. Oncology, 20: 615-20

Folkman, J., and Y. Shing 1992 Angiogenesis. J. Biol. Chem., 267: $10931-4$

Fujii, T., K. Shimada, O. Asai, N. Tanaka, K. Fujimoto, K. Hirao, N. Konishi 2013 Immunohistochemical analysis of inflammatory cells in benign and precancerous lesions and carcinoma of the prostate. Pathobiology, 80: 119-26

Gallo, O., A. Franchi, L. Magnelli, L. Sardi, A. Vannacci, V. Boddi, V. Chiarugi, and E. Masin 2001 Cyclooxygenase-2 pathway correlates with VEGF expression in head and neck cancer. Implications for tumor angiogenesis and metastasis. Neoplasia, 3: $53-61$

Geller, J., L. Sionit, C. Partido, L. Li, X. Tan, T. Youngkin, D. Nachtsheim, and R. M. Hoffman 1998 Genistein inhibits the growth of human-patient BPH and prostate cancer in histoculture. Prostate, 34: 75-9

Harper, M. E., E. Glynne-Jones, L. Goddard, V. J. Thurston, and K. Griffiths 1996 Vascular endothelial growth factor (VEGF) expression in prostatic tumours and its relationship to neuroendocrine cells. Br. J. Cancer, 74: 910-6

Howe, L. R. 2007 Inflammation and breast cancer. Cyclooxygenase/prostaglandin signaling and breast cancer. Breast Cancer Res., 9: 210

Hsu, A. L., T. T. Ching, D. S. Wang, X. Song, V. M. Rangnekar, and C. S. Chen 2000 The cyclooxygenase-2 inhibitor celecoxib induces apoptosis by blocking Akt activation in human prostate cancer cells independently of Bcl-2. J. Biol. Chem., 275: 11397-403

Khan, Z., N. Khan, R. P. Tiwari, N. K. Sah, G. B. Prasad, and P. S. Bisen 2011 Biology of Cox-2: an application in cancer therapeutics. Current Drug Targets, 12: 1082-93

Kuiper, G. G., B. Carlsson, K. Grandien, G. G. Kuiper, B. Carlsson, K. Grandien, E. Enmark, J. Häggblad, S. Nilsson, and J. A. Gustafsson 2004 Comparison of the ligand binding specificity and transcript tissue distribution of estrogen receptors alpha and beta. Endocrinology, 138: 863-70

Kulinsky, V. I. 2007 Biochemical aspects of inflammation. Biochemistry, 72: 595-607

Kurahashi, N., M. Iwasaki, S. Sasazuki, T. Otani, M. Inoue, and S. Tsugane 2007 Soy product and isoflavone consumption in relation to prostate cancer in Japanese men. Cancer Epidemiol. Biomarkers Prev., 16: 538-45

Li, Y., Z. Wang, D. Kong, R. Li, S. H. Sarkar, and F. H. Sarkar 2008
Regulation of Akt/FOXO3a/GSK-3beta/AR signaling network by isoflavone in prostate cancer cells. J. Biol. Chem., $\mathbf{2 8 3}$ 27707-16

Liu, X. H., S. Yao, A. Kirschenbaum, and A. C. Levine 1998 NS398, a selective cyclooxygenase-2 inhibitor, induces apoptosis and down-regulates bcl-2 expression in LNCaP cells. Cancer Res., 58: 4245-9

Marcelli, M., G. R. Cunningham, M. Walkup, Z. He, L. Sturgis, C. Kagan, R. Mannucci, I. Nicoletti, B. Teng, and L. Denner 1999 Signaling pathway activated during apoptosis of the prostate cancer cell line LNCaP: overexpression of caspase- 7 as a new gene therapy strategy for prostate cancer. Cancer Res., $\mathbf{5 9}$ $382-90$

Marcelli, M., M. Marani, X. Li, L. Sturgis, S. J. Haidacher, J. Trial, R. Mannucci, I. Nicoletti, and L. Denner 2000 Heterogeneous apoptotic responses of prostate cancer cell lines identify an association between sensitivity to staurosporine-induced apoptosis, expression of Bcl-2 family members, and caspase activation. Prostate, 42: 260-73

Masferrer, J. L., K. M. Leahy, A. T. Koki, B. S. Zweifel, S. L. Settle, B. M. Woerner, D. A. Edwards, A. G. Flickinger, R. J. Moore, and K. Seibert 2000 Antiangiogenic and antitumor activities of cyclooxygenase-2 inhibitors. Cancer Res., 60: 1306-11

Mutter, R., B. Lu, D. P. Carbone, I. Csiki, L. Moretti, D. H. Johnson, J. D. Morrow, A. B. Sandler, Y. Shyr, F. Ye, and H. Choy 2009 A phase II study of celecoxib in combination with paclitaxel, carboplatin, and radiotherapy for patients with inoperable stage IIIA/B non-small cell lung cancer. Clin. Cancer Res., 15: $2158-65$

Narayanan, B. A., N. K. Narayanan, L. Davis, and D. Nargi 2006 RNA interference-mediated cyclooxygenase-2 inhibition prevents prostate cancer cell growth and induces differentiation: modulation of neuronal protein synaptophysin, cyclin D1, and androgen receptor. Mol. Cancer Ther., 5: 1117-25

Oh, H. Y., J. Leem, S. J. Yoon, S. Yoon, and S. J. Hong 2010. Lipid raft cholesterol and genistein inhibit the cell viability of prostate cancer cells via the partial contribution of EGFR-Akt/p70S6k pathway and down-regulation of androgen receptor. Biochem. Biophys. Res. Commun., 393: 319-24

Palayoor, S. T., M. J. Arayankalayil, A. Shoaibi, and C. N. Coleman 2005 Radiation sensitivity of human carcinoma cells transfected with small interfering RNA targeted against cyclooxygenase-2. Clin. Cancer Res.,11: 6980-6

Palayoor, S. T., E. A. Bump, S. K. Calderwood, S. Bartol, and C. N. Coleman 1998 Combined antitumor effect of radiation and ibuprofen in human prostate carcinoma cells. Clin. Cancer Res., 4: 763-71

Park, S. K., L. C. Sakoda, D. Kang, A. P. Chokkalingam, E. Lee, H. R Shin, Y. O. Ahn, M. H. Shin, C. W. Lee, D. H. Lee, A. Blair, S. S. Devesa, A. W. Hsing 2006 Rising prostate cancer rates in South Korea. Prostate, 66: 1285-91

Peterson, G., and S. Barnes 1993 Genistein and biochanin A inhibit the growth of human prostate cancer cells but not epidermal growth factor receptor tyrosine autophosphorylation. Prostate, 22: $335-45$

Phillips, R. K., M. H. Wallace, P. M. Lynch, E. Hawk, G. B. Gordon, B. P. Saunders, N. Wakabayashi., Y. Shen, S. Zimmerman, L Godio, M. Rodrigues-Bigas, L. K. Su, J. Sherman, G. Kelloff, B. Levin, G. Steinbach and FAP Study Group 2002 A randomised, double blind, placebo controlled study of celecoxib, a selective cyclooxygenase 2 inhibitor, on duodenal polyposis in familial adenomatous polyposis. Gut, 50: 857-60

Platz, E. A., and A. M. De Marzo 2004 Epidemiology of inflammation and prostate cancer. J. Urol., 171: S36-40

Rice-Evans, C. A., N. J. Miller, P. G. Bolwell, P. M. Bramley, and J. B. Pridham 1995. The relative antioxidant activities of plantderived polyphenolic flavonoids. Free Radic. Res., 22: 37583

Rizzo, S., G. Attard, and D. L. Hudson 2005 Prostate epithelial stem cells. Cell Prolif., 38: 363-74

Siegel, R., D. Naishadham, and A. Jemal 2012 Cancer statistics, 2012. CA Cancer J. Clin., 62: 10-29 
Sobolewski, C., C. Cerella, M. Dicato, L. Ghibelli, and M. Diederich 2010 The role of cyclooxygenase- 2 in cell proliferation and cell death in human malignancies. Int. J. Cell Biol., 2010: 215158

Steinbach, G., P. M. Lynch, R. K. Phillips, M. H. Wallace, E. Hawk, G. B. Gordon, N.Wakabayashi, B. Saunders, Y. Shen, T. Fujimura, L. K. Su, B. Levin, L. Godio, S. Patterson, M. A. Rodriguez-Bigas, S. L. Jester, K. L. King, M. Schumacher, J. Abbruzzese, R. N., DuBois, W. N. Hittelman, S. Zimmerman, J.W. Sherman, G. Kellof 2000 The effect of celecoxib, a cyclooxygenase-2 inhibitor, in familial adenomatous polyposis. N. Engl. J. Med., 342: 1946-52

Taplin, M. E., and S. P. Balk 2004 Androgen receptor: a key molecule in the progression of prostate cancer to hormone independence. J. Cell Biochem., 91: 483-90

Tran, C., S. Ouk, N. J. Clegg, Y. Chen, P. A. Watson, V. Arora, J.
Wongvipat, P. M. Smith-Jones, D. Yoo, A. Kwon, T. Wasielewska, D. Welsbie, C. D. Chen, C. S. Higano, T. M. Beer D. T. Hung, H. I. Scher, M. E. Jung, C. L. Sawyers 2009 Development of a second-generation antiandrogen for treatment of advanced prostate cancer. Science, 324: 787-90

Tsujii, M., S. Kawano, and R. N. DuBois 1997 Cyclooxygenase-2 expression in human colon cancer cells increases metastatic potential. Proc. Natl. Acad. Sci. U. S. A., 94: 3336-40

Uefuji, K., T. Ichikura, and H. Mochizuki 2000 Cyclooxygenase-2 expression is related to prostaglandin biosynthesis and angiogenesis in human gastric cancer. Clin. Cancer Res., 6: 135-8

Yao ,M., E. C. Lam, C. R. Kelly, W. Zhou, and M. M. Wolfe 2004 Cyclooxygenase-2 selective inhibition with NS-398 suppresses proliferation and invasiveness and delays liver metastasis in colorectal cancer. Br. J. Cancer., 90: 712-9 